\title{
Evaluation of the Effect of Organizational Citizenship Behaviour on Organizational Commitment among Nurses, by Structural Equations Model
}

\author{
Hosein Baloochi ${ }^{1}$, Hassan Baloochi² ${ }^{2}$ Seyedeh Masoumeh Saadati ${ }^{3}$ \\ ${ }^{1}$ Department of Business Management, Semnan University, Semnan, Iran. ${ }^{2}$ Research Committee Neyshabur University \\ Medical of Sciences. ${ }^{3}$ Department of Operation Room, Neyshabur University of Medical Sciences, Neyshabur, Iran.
}

\section{ABSTRACT}

\section{BACKGROUND}

The present research explores practical approaches for improving nurses' organizational commitment based on organizational citizenship behaviour and its dimensions.

\section{METHODS}

This research is practical in purpose and is considered to be a descriptivecorrelational study. First, theoretical model and between-variables' hypotheses were developed. Structural equations model was used to explore the research hypotheses. Nurses in hospitals located in Neyshabur and Gonabad were included. Based on Morgan table and using purposive sampling method, 190 participants were chosen. Data collection was conducted by means of two questionnaires including Allen \& Meyer's Organizational Commitment Questionnaire and Organ organizational citizenship behaviour questionnaire. Reliability of the questionnaires was assessed using Cronbach's alpha and composite reliability while convergent and divergent validity were checked.

\section{RESULTS}

The results indicated that organizational citizenship behaviour positively affects organizational commitment. Also, the effects of organizational citizenship behaviour constructs on organization commitment were confirmed. The effect of sportsmanship on organizational commitment was not approved.

\section{CONCLUSIONS}

High level managers and researchers could get a better understanding of the effect of organizational variables on improved satisfaction among clients and employees using focal correlation.

\section{KEY WORDS}

Organizational Citizenship Behaviour, Organizational Commitment, Composite Reliability
Corresponding Author:

Seyedeh Masoumeh Saadati, Department of Operation Room,

Neyshabur University of Medical Sciences, Neyshabur, Iran.

E-mail: hadismast@gmail.com

DOI: 10.14260/jemds/2019/759

Financial or Other Competing Interests: None.

How to Cite This Article:

Baloochi H, Baloochi H, Saadati SM. Evaluation of the Effect of organizational citizenship behaviour on organizational commitment among nurses, by structural equations model. J. Evolution Med. Dent. Sci. 2019;8(47):3508-3514, DOI: $10.14260 /$ jemds/2019/759

Submission 21-08-2019,

Peer Review 15-10-2019,

Acceptance 22-10-2019,

Published 25-11-2019. 


\section{BACKGROUND}

Strong relations between organization and their employees could improve employees' motivation towards their jobs and their tendency to deliver better service to the costumers at the same time.(1) Various research has proved that employees treat customers the same way that organization treats them. In other words, if employees feel that organization holds value and respect for them, they show this attitude and behaviour in interactions with costumers. However, if they recognize that their manager is inattentive to their needs and demands, they behave indifferent toward costumers.(2) Common phenomena such as reduced organizational performance and commitment, increased emotional exhaustion,(3) anti-production behaviours, ${ }^{(4)}$ reduced function and spirit(5) and anti-citizenship behaviours, negative feelings, altered attitude among employees towards managers and their organizations are among major markers of problems that human resource managers have faced during recent years. (6) There are employees that do not trust in managers and organizations anymore. They feel underpaid with continuous decrease in their payments due to mandatory fees for retirement and health service expenses.

They believe that their job is bad, and this increases their frustration. However, a few number of employees actually show their dissatisfaction and discuss this with their managers, instead, they mostly turn to aggressive, passive behaviours which are detrimental to the organization.(7) In the meantime, service organizations specially hospitals which are among most active entities in service industries worldwide, are facing more serious problems due to nature and characteristics specific to the employees in this industry. A new approach in order to manage and control these factors and increase organizational productivity is organizational citizenship behaviour. Organ (1983) states that organizational citizenship behaviour is a conscious, voluntary and transactional behaviour which is effective in increasing organizational functioning but is not appreciated through formal reward system within organizations, directly or indirectly.(8) Introduction of concepts such as ethics, truth, search for meaning in work, sodality with co-workers, altruism in work place and etc. all indicate the development of this new paradigm.(9) Managers place special emphasis on adopting positive approaches for development and management of human resources in work environments.(10) Literature review shows that organizational citizenship behaviour is associated with outcomes such as organizational commitment,(11) function, job satisfaction and pleasure at $\operatorname{work}^{(12)}$ and leads to lower turnout intention.(13) Also, research indicates that individuals with high organizational commitment tend to show more organizational citizenship behaviour.(14) Overall, organizational commitment has major effects on behaviour and function in groups and organizations. Individual outcomes of organizational commitment are: belonging and attachment, safety, positive self-image, organizational rewards. Consequences of organizational commitment for group activities include membership stability, more solidarity and effectiveness of the group.

Organizational results are: continuous endeavour, lower rate of quitting jobs, reduced absenteeism and delay and better performance.(15) Finally, it could be stated that these approaches aim to identify constructs and ways to improve employees' well-being.(10) Despite the importance of positive aspects of organizational behaviour, few research and attempts, theoretical or experimental, have been conducted to explore the effect of organizational citizenship behaviour on organizational commitment in hospitals. Since managerial systems in Iran's universities of medical sciences are somewhat different, a comparison between two large but different organizations could gain more clear responses. The present study was carried out in order to examine the association between organizational citizenship behaviour and organizational commitment among nurses in hospitals located in Neyshabur and Gonabad. Organizational citizenship behaviour is a series of voluntary behaviours which are not a part of individual's formal duties, but they perform them and lead to effective improvement of organizational roles and functions. Organ defines organizational citizenship behaviour as a conscious and spontaneous behaviour which is not directly or explicitly anticipated in formal reward system but leads to improved organizational function altogether.(16) Conscious and spontaneous behaviour means that this behaviour is not mandatory to the job or is not within defined duties, but instead, it is a personal choice with no consequences in case it is not accomplished.(17) Despite increased attention to the concept of organizational citizenship behaviour, a literature review indicates lack of consensus regarding various aspects of this concept. The results of this literature review indicate that almost 30 different types of citizenship behaviour exist with multiple descriptions and lots of overlaps between theses descriptions. However, there is no consensus about various aspects of organizational citizenship behaviour. In fact, the most validated classification of organizational citizenship behaviour constructs has been provided by Organ which has been widely used in research.

Organ (1988) developed a multidimensional scale of organizational citizenship behaviour with 5 dimensions, namely(18) Altruism (voluntary behaviours with motivation to help colleagues and staffs to cope with their organizationally relevant task or problem), Conscientiousness (performing the assigned tasks in a manner beyond what is expected), Sportsmanship (tolerating unexpected conditions and events without any complaint), Civic Virtue (efficient participation in operations of the organization considering company's work process) and Courtesy (voluntary behaviours which prohibit work-related problems with others(19))

\section{Organizational Commitment}

With introduction of commitment in management and organization literature, organizational commitment has been widely studied and various definitions have been presented. Based on a study by Noy et al (1994), organizational commitment is the extent an employee knows an organization and how much that employee is willing to have an impact on the operations of the organization. In other words, organizational commitment is how employees feel about their jobs and could be defined as the bond employees experience with their organization.(20) Robbins (2005) describes organizational commitment as a state in that 
employees identify with the organization and wish to remain part of the organization. In other words, organizational commitment is an attitude regarding employees' loyalty to the organization and a continuous process which leads to the success and well-being of the organization through employees' participation in organizational decisions and their interest. Meyer and Allen (1984) proposed a threecomponent model to conceptualize organizational.

\section{Commitment}

Affective commitment, normative commitment and continuance commitment. Affective commitment is the most component of the organizational commitment which refers to the extent to are emotionally attached, and are involved in the organization. Factors such as belief in organizational culture, purposes and values, willingness to exert considerable effort on behalf of the organization and its objectives and a strong desire to maintain membership in the organization indicate high affective commitment of organization human resource. Normative commitment is the second component of the organizational commitment. It reflects a feeling of obligation to remain in an organization. The last component, continuance commitment is an employee's awareness of the costs associated with leaving the organization. In case of leaving the organization, some financial investments including insurance, loans among others would be lost.(21) These components are overlapping yet independent and could be calculated separately.(22) There are some investigations regarding the effect of organizational citizenship behaviour and organizational commitment which will be discussed in the following section. In a study titled as the effect of work climate on critical employee and customer outcomes: an employee-level analysis, Yoon et al (2001) showed that service climate and managers' support for employees are related to work efforts and job satisfaction and indirectly have impact on customers' perceptions of employee service quality. Also, investigations indicate the positive role of internal marketing which means employees focus their effort to satisfy needs and demands of foreign customers.(23)

Morin and colleagues carried out a research titled as normative commitment and organizational citizenship behaviour in 2010. They recruited 216 sport managers. Statistical tests using structural equations modelling were used. The results revealed that employees' and managers' commitments were positively and significantly associated with OCB. Results also indicated cross-foci relationships between aspects of organizational commitment and OCB.(24) Foote et al in 2007 conducted a study to find out if team commitment leads to team cohesion. In this research, team commitment moderates the relationship between job satisfaction and OCB. 242 questionnaires were completed by employees at manufacturing facilities. Multivariate regression was used to test hypotheses. Findings confirmed the moderating role of commitment in the relationship between job satisfaction and OCB. Also, a positive and significant association between commitment and OCB was found such that when team commitment was higher, the relationship seemed to be stronger.(25)

Pour Sultani Zarandi and Amirji Naghdar (1390) performed a study regarding organizational commitment in sports teachers in the city of Mashahd in 1390.
All physical education teachers in Mashhad schools $(\mathrm{N}=1200)$ were considered and finally 291 was calculated as sample size using Morgan tables. For data collection, two standard questionnaires of organizational commitment and organizational citizenship behaviour(16) were used. Validity was assessed based on revisions carried out by sports management experts. Internal reliability of both questionnaires was estimated to be 0.85 and 0.76 , respectively. Descriptive-correlation research method was carried out. Data analysis was performed using descriptive statistics, Kolmogorov-Smirnov test, Pearson correlation coefficient and multiple regressions. Normality of the data was confirmed by Kolmogorov-Smirnov test results $(p>0.05)$. Correlation test revealed a positive and significant association between organizational commitment and OCB with correlation coefficient of 0.349 at significance level of 0.01. Also, regression results showed that among organizational commitment components, affective commitment predicted teachers' OCB with more statistical power (Pour Zarandi Sultani and Amirji Naghdar, 1390).(26)

The effect of organizational citizenship behaviour education on organizational commitment was explored by Allah Tavakoli Zainab. Abedi Mohammad Reza. Munira Saleh. (1388). Population of the study included employees at entertainment and cultural department of Isfahan municipality in 1386. Participants in the intervention group attended 6 educational sessions about OCB. Measurement tools included two scales of OCB and OC (pre- and post-test) and data analysis was carried out by Covariance analysis. Results revealed that OCB education leads to increased OC, affective commitment and normative commitment without significant effect on increased continuance commitment.(27)

Another research was carried out by Abili Khudayar. Haiat Ali Asghar. Choopani Haide. And Keramat Keramat titled as the association between organizational commitment and organizational citizenship behaviour among experts in Tehran University". It was a descriptive-analytical research. 1530 experts in Tehran University were recruited. 136 participants were finally selected using Cochrane formula with simple random sampling method. Allen and Meyer's organizational commitment questionnaire and organizational citizenship behaviour questionnaire developed by Podsakoff (1990) were used with reliability of 0.87 and 0.71 , respectively, using Cronbach's alpha coefficient. Pearson correlation coefficient and multivariate regression and independent-T tests were used for data analysis. Pearson correlation results indicated a positive and significant association between overall organizational commitment with altruism, sportsmanship and conscientiousness. Among components of organizational commitment, only affective commitment was significantly associated with overall organizational citizenship behaviour. Regression analysis showed that only affective commitment predicts overall OCB of the experts. T-test results revealed that OCB was significantly different in terms of gender with women having higher mean scores.(28) Research hypotheses and model.

Based on purpose and research background, following hypotheses are defined-

\section{Primary Hypothesis}

OCB is positively and significantly effective on nurses' organizational commitment. 


\section{Secondary Hypotheses}

- $\quad$ Sportsmanship component of citizenship behaviour has significant positive effect on organizational commitment.

- Altruism component of citizenship behaviour has significant positive effect on organizational commitment.

- Consciousness component of citizenship behaviour has significant positive effect on organizational commitment.

- $\quad$ Civic virtue component of citizenship behaviour has significant positive effect on organizational commitment.

- Courtesy component of citizenship behaviour has significant positive effect on organizational commitment.

\section{METHODS}

The present study aims to develop practical application of human relation variables in organization which makes it an applied research. Since a description of variables and associations between them is presented in order to recognize existing conditions and adopting optimal decisions, this research is considered to be descriptive. On the other hand, because the associations between variables are analysed based on study purpose, therefore, this is a correlation study based on structural equations. We explored the effect of OCB on organizational commitment among nurses in hospitals. Nurses working at hospitals located in Neyshabur and Gonabad, Iran, were selected. A sample size of 340 including 180 nurses in Neyshabur and 180 in Gonabad city was considered with a minimum of 180 based on Morgan table. Sampling was carried out between 1393 and 1394 during 5 months using purposive sampling method. 200 questionnaires were collected and analysed by authors and 10 were removed due to less than $50 \%$ of questions being answered. The questionnaire included 3 sections: 1) a brief discussion about the title of the research and an introduction 2) general information including age, income and history, 3) 15 organizational commitment questions using Allen and Meyer's standard questionnaire (1984) and citizenship behaviour questions including 23 questions using Organ questionnaire (1988). These are closed-questions which are answered based on 5-point Likert scale. Cronbach's alpha (29) and composite reliability(30) were used to examine reliability of the questionnaires. Composite reliability for OCB and organizational commitment were 0.75 and 0.87 , respectively. The results revealed high reliability of the questionnaire.(31) Table (1) Shows that this questionnaire has the necessary reliability. It is noteworthy that we did not remove any of the questions due to inadequate data or lack of its associated variable's variance.

\section{Statistical Analysis}

Factor validity was used for validity assessment. Factor validity is a form of construct validity which is calculated through factor analysis. Factor analysis is a statistical technique used in most human sciences. In explanatory factor analysis of OCB and organizational commitment, KMO of 0.837 and 0.908 was calculated which indicates efficacy of sample size for study variables. Also, considering Bartlett's test significance coefficient of 0 (lower than 0.05), factor analysis for structure identification was considered as appropriate. Confirmatory factor analysis was used to test validity of measurement models with the results indicating factor loadings higher than 0.5 which shows convergent validity. AVE was used for divergent validity which was calculated as 0.51 and 0.79 for OCB and organizational commitment, respectively. Structural models was used to explore associations between endogenous and exogenous latent variables. Pearson correlation coefficient test was used to examine the association between overall organizational commitment with altruism, sportsmanship and conscientiousness.

\section{RESULTS}

First, demographic characteristics of study participants were examined using descriptive statistics. Then, hypotheses were explored.

\section{Measurement models of Study Variables}

Prior to testing hypotheses and conceptual models, it is necessary to make sure about validity of research variables measurement models. This was carried out by confirmatory factor analysis. The results for all research variables showed that all measurement models were valid, and all numbers and parameters were significant. Considering all factor loadings in all dimensions and average variance extracted (AVEs) were higher than 0.5 , construct validity in the form of convergent validity was confirmed. The results of factor analysis are presented in. First-order confirmatory factor analysis (The questionnaire's factor analysis) revealed that all questions have the necessary validity for measurement of study variables. The criteria for confirmation or rejection of a question for measurement of a variable is significance figure. If significance number is higher than 1.96 or lower than -1.96 , that question is appropriate for measurement of intended aspect. However, if the significance number is among that range, the question is not valid enough for that aspect.

\section{Correlation between Study Variables}

In correlation analysis, null hypothesis (H0) and the opposite hypothesis (H1) are as follows-

\section{HO}

Correlation coefficient is equal to 0 (no significant correlation between two variables).

\begin{tabular}{|c|c|c|c|c|c|c|c|}
\hline 党 & 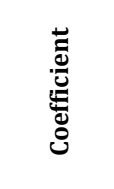 & 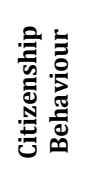 & 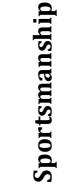 & 吾 & 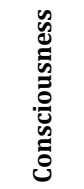 & 节 & 苞 \\
\hline $\begin{array}{c}\text { Organizational } \\
\text { commitment }\end{array}$ & $\begin{array}{c}\text { Pearson } \\
\text { coefficient }\end{array}$ & $0 / 698$ & $0 / 360$ & $0 / 495$ & $0 / 542$ & $0 / 422$ & $0 / 326$ \\
\hline Table & $\begin{array}{l}\text { 1. Pearso } \\
\text { Associ }\end{array}$ & $\begin{array}{l}\text { Corre } \\
\text { ion } b\end{array}$ & $\begin{array}{l}\text { on Co } \\
\text { een } S\end{array}$ & $\begin{array}{l}\text { ficient } t \\
\text { dy Vario }\end{array}$ & $\begin{array}{l}\text { Exam } \\
\text { bles }\end{array}$ & ne the & \\
\hline
\end{tabular}

H1

Correlation coefficient is not equal to 0 (Significant correlation between two variables). As the results in the following table show, significant positive correlations exist 
between study variables. Therefore, at 95\% confidence interval, the null hypothesis is rejected and the opposite hypothesis (A significant association) is approved (Table 1).

\section{Model Fit Indices}

In order to examine conceptual model's goodness of fit, 8 common indices along with acceptable value for each index recommended in previous research were used (Hair et al, 1998). Fit indices show to what extent research conceptual model is competent in measurement of intended research population. In other words, to what extent collected data support study model. It should be noted that there are various factors affecting these indices. For instance, some are highly sensitive to sample size. Therefore, all indices should be considered in case of model fit and low model fit values in one or more indices does not mean the lack of fit. Table (2) Shows that primary and secondary conceptual models of the present research fit well with the observed data.

\begin{tabular}{|c|c|c|c|}
\hline Reliable Value & $\begin{array}{c}\text { Model } \\
\text { Statistic }\end{array}$ & $\begin{array}{c}\text { Goodness } \\
\text { of Fit Index }\end{array}$ & Desirability \\
\hline$<5$ & $2 / 11$ & $\mathrm{X} 2 / \mathrm{df}$ & Model approved \\
\hline$<0.08$ (Joreskong and Sorbom, 1996) & $0 / 077$ & $\mathrm{RMSEA}^{1}$ & Model approved \\
\hline$<0.08$ (Bentler, 1990) & $0 / 038$ & $\mathrm{RMR}^{2}$ & Model approved \\
\hline$>0.80$ (Fornel and Larcker, 1981) & $0 / 94$ & $\mathrm{NFI}^{3}$ & Model approved \\
\hline$>0.80$ (Bagozzi and Yi, 1988 & $0 / 95$ & $\mathrm{NNFI}^{4}$ & Model approved \\
\hline$>0.80$ (Joreskong and Sorbom, 1996) & $0 / 97$ & $\mathrm{CFI}^{5}$ & Model approved \\
\hline$>0.80$ (Bagozzi and Yi, 1988) & $0 / 95$ & $\mathrm{GFI}$ & Model approved \\
\hline$>0.80$ (Etezadi-Amoli and Farhoomand, & $0 / 90$ & AGFI & Model approved \\
\hline 1996) & Table 2. The Goodness of Fit Indices \\
\hline \multicolumn{4}{|l|}{} \\
\hline
\end{tabular}

\section{Structural Equations Modelling (Research Structural Model)}

Structural models explore associations between endogenous and exogenous latent variables. The present study includes two models. First model examines the primary hypothesis in which organizational citizenship behaviour (OCB) and organizational commitment are considered as exogenous latent variable and endogenous latent variable, respectively. In second model, secondary hypotheses (The effect of citizenship behaviour dimensions on organizational commitment) are explored.
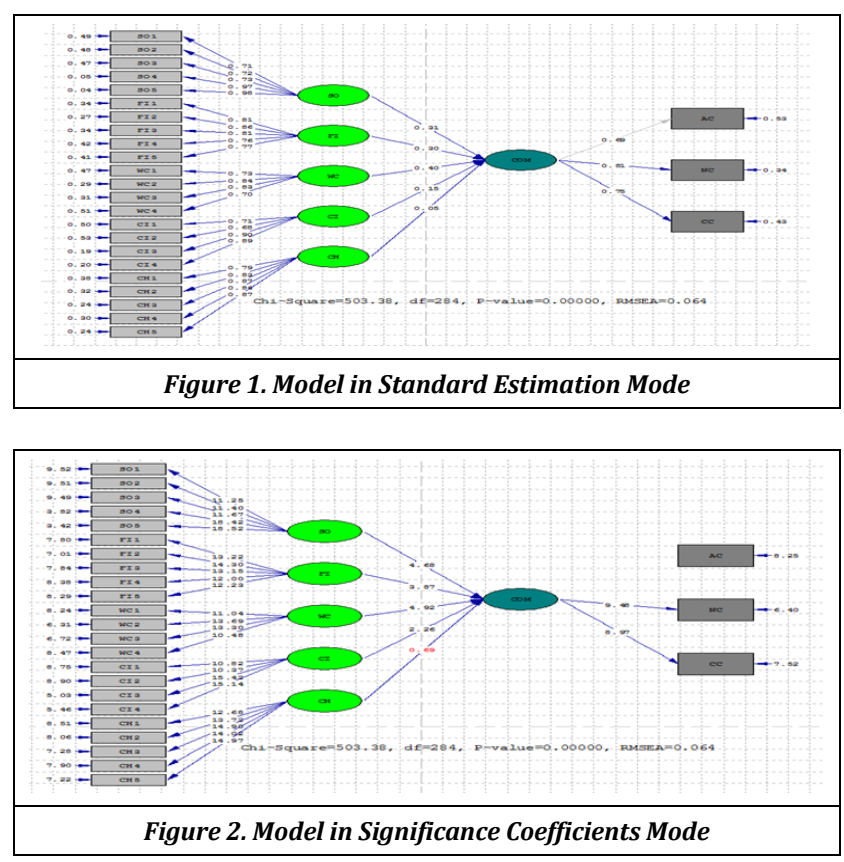

The following model aims to examine and test the effects of organizational citizenship behaviour dimensions on organizational commitment. Civic virtue (SO), altruism (FI), consciousness (CI) and sportsmanship ( $\mathrm{CH}$ ) are exogenous latent variables and organizational commitment is endogenous latent variable. (Figure 1,2) Overall, significance level is determined based on critical points of 1.96 and -1.96 such that if significance coefficient is higher than 1.96 or lower than -1.96 , the null hypothesis is accepted, and a significant association is approved.

\section{DISCUSSION}

Today, quality and appropriate service to patients and clients in hospitals is among necessities of health systems in the country. As such, long-term customer satisfaction, loyalty and re-visit happen. With increase in the number of clinics and private and government health centers, providing appropriate service in hospitals and government centers is increasingly important. Considering health centers and hospitals are in service-industry, human resources play a major role in delivery of quality service. Efficient human resources have the ability to attract customers (clients) to the organization. An important source of competitive advantage in many health and service centers is having educated, efficient and tact work force. In the meantime, role of nurses due to contact and communication with patients and clients is of major significance. A good nurse could improve credibility of an organization and change clients' view regarding the quality of service. Attention to nurses' environment, their interactions and their commitment to organization leads to work conditions' improvement and delivering more desirable service to ultimate customers (Patients and clients). Therefore, aim of the present study was to examine the effect of OCB on organizational commitment in two cities including Neyshabur and Gonabad. Hypotheses were developed using literature review. Then, hypotheses were examined.

Primary research hypothesis explored the effect of OCB on nurses' organizational commitment. Results of correlation test and path analysis confirmed this hypothesis. Correlation coefficient (Two-way association) of variables was 0.698 which indicates high correlation between variables. Path coefficient was 0.98 with significance value of 9.2 which shows significant positive effect of OCB on nurses' organizational commitment. It means that with each unit change in OCB, the commitment to hospital and service center is expected to increase by 0.98 . Secondary hypotheses were then explored to assess the effect of OCB dimensions on OC.

A significant positive effect of civic virtue on OC was observed with effect size of 0.31 and significance value of 4.67. This means that with 1 unit increase in social virtues (civic behaviour), nurses' commitment level is expected to increase by 0.3 . Significance value for altruism and its effect size were 3.78 and 0.31 , respectively. This indicates significant positive association between altruism and nurses' organizational commitment. The effect size of consciousness, highest among all dimensions, was equal to 0.40 with significance number of 4.92 . With 1 unit increase in OCB, organizational commitment is expected to increase by 0.40 . 
The lowest effect size was observed for courtesy. The effect size of this dimension was 0.15 which considering significance value of 2.26 is significant and positive. This means with 1-unit increase in courtesy, nurses' organizational commitment is expected to increase by 0.15 . In terms of sportsmanship, considering significance value of 0.069 , which is somewhere between 1.96 and -1.96 , this hypothesis was rejected. Results of the present study are in line with previous researches $(24,25)$. Only in case of sportsmanship dimension, the results are inconsistent with other studies. Descriptive statistics indicate that variables and their dimensions are less than moderate. This demonstrates the presence of some issues and problems in terms of organizational behaviour and human resource in the hospital. Due to high work pressures and low level of salary and benefits compared to other medical professions, nurses often express dissatisfaction with their job and work conditions. Low organizational commitment and its dimensions show this issue. Night shifts, stressful work environments and various high-risk responsibilities are among factors leading to reduced organizational commitment and burnout among nurses. Considering these results, it is recommended to managers to pay more attention to organizational sources and employees' organizational commitment. Stressful work environment results in psychological problems in nurses and those who should care for patients, develop depressive disease and mental exhaustion in long term. Therefore, it is recommended to reduce environmental pressures for nurses by creating relaxing work conditions. Job rotations lead to diverse work conditions and prevent job boredom. In order to increase continuance commitment among nurses, salary and benefits should be improved based on performance appraisal system. Out-of-organization activities and associations promote affective relationships and bonds between organization and nurses. Attention to promotion and reward systems, in addition to increased continuance commitment, is positively associated with increased normative commitment among employees. In order to improve OCB and its dimensions, it is necessary to consider nurses' culture and values. Encouragement and appreciation of employees' sacrifices, physical or spiritual, improves motivation to exercise behaviours such as altruism, sportsmanship and social virtue.

\section{CONCLUSIONS}

Programs such as employee of the month, attention to patients' comments and suggestions lead to higher motivation among nurses in terms of courtesy and social virtue. This research, like many others, has limitations including limited statistical population which reduces the generalizability of the results. In future studies, it is recommended that researchers further explore the effect of OCB on organizational commitment dimensions and to expand their efforts. Using foci-correlation in order to examine this association helps to better understand this research topic.

\section{REFERENCES}

[1] Oluseye 0. Assessing the effect of organizational commitment on service quality: a study of customercontact employee. Global Journal of Management And Business Research 2011;11(2).

[2] Greg LS, Kent JB. Human Resource Management "link strategy and action". $1^{\text {st }}$ edn. Mahkameh 2012.

[3] Johnson JL, O'Leary-Kelly AM. The effects of psychological contract breach and organizational cynicism: not all social exchange violations are created equal. Journal of Organizational Behaviour: The International Journal of Industrial, Occupational and Organizational Psychology and Behaviour 2003;24(5):627-47.

[4] Wilkerson JM, Evans WR, Davis WD. A test of co-workers' influence on organizational cynicism, badmouthing and organizational citizenship behaviour. Journal of Applied Social Psychology 2008;38(9):2273-92.

[5] Cordes CL, Dougherty TW. A review and an integration of research on job burnout. Academy of Management Review 1993;18(4):621-56.

[6] Poshti RRF, Nusratullo MZ. Human resource development: Publishing Industrial Management, 2009.

[7] Balochi H, Rategar AA. Modeling the structuralinterpretation of the factors affecting organizational cynicism. Governance Organization Management 2015;3(3):71-91.

[8] Markóczy L, Xin K. The virtues of omission in organizational citizenship behaviour. University of Californial: Published Thesis at The University of California, River side, United States 2004.

[9] Shaigan D. New charm, style and thinking patchwork mobile. Tehran: Farzan Roz 2002.

[10] Fayyazi M, Symar Asl N, Kaveh M. Positive psychology in leadership and management of the organization (growing movement). National Conference leadership and management challenges in Iranian organizations: Islamic Azad University, Science and Research 2010.

[11] Gautam T, Van Dick R, Wagner U, et al. Organizational citizenship behaviour and organizational commitment in Nepal. Asian Journal of Social Psychology 2005;8(3):30514.

[12] Youssef CM, Luthans F. Positive organizational behaviour in the workplace: the impact of hope, optimism and resilience. Journal of Management 2007;33(5):774-800.

[13] Bressler ME. Relationship between hope, optimism, organizational commitment and turnover intention among US Army Reserve Soldiers. University of HoustonClear Lake 2006.

[14] Bolon DS. Organizational citizenship behaviour among hospital employees: a multidimensional analysis involving job satisfaction and organizational commitment. Hospital \& Health Services Administration 1997;42(2):221-41.

[15] Lee GB. Dissertation examines the impact of organizational culture on organizational commitment. Qom Tehran University campus, 2000. 
[16] Organ DW, Konovsky M. Cognitive versus affective determinants of organizational citizenship behaviour. Journal of Applied Psychology 1989;74(1):157-64.

[17] Shateri K, Youzbashi A, Nooralizadeh R. Compulsory citizenship behaviour in organizations. Prudence 2010: p. 212.

[18] Senobari M. Organizational Citizenship Behaviour. Journal of Police Human Development 2007;7(16).

[19] Navabakhsh M. Management of organizational citizenship behaviour in function of social context. Basirat 2010;16(43).

[20] Lipiniskiene D. The examinational relationship between organizational commitment and job satisfaction of employees. Ekonomika Irvadyba Aktualijos Ir Perspektyvos 2008;4(13):282-9.

[21] Reza SJS, Marjan F, Hosein B. The effect of psychological capital on the quality of the offered services to the clients by the counter staffs with organizational commitment meditation. Journal of Public Administration 2015;7(2):277-302.

[22] Gelade GA, Dobson P, Gilbert P. National differences in organizational commitment: effect of economy, product of personality or consequence of culture? Journal of Cross-Cultural Psychology 2006;37(5):542-56.

[23] Yoon HM, Beatty SE, Suh J. The effect of work climate on critical employee and customer outcomes: an employeelevel analysis. International Journal of Service Industry Management 2001;12(5):500-21.
[24] Morin AJS, Vandenberghe C, Boudrias JS, et al. Affective commitment and citizenship behaviours across multiple foci. Journal of Managerial Psychology 2011;26(8):71638.

[25] Foote DA, Tang LPT. Job satisfaction and organizational citizenship behaviour (OCB) does team commitment make a difference in self-directed teams? Management Decision 2008;46(6):933-47.

[26] Sultani PZH, Naghdar AR. Organizational Commitment communication education teachers for the city of Mashhad in 2012. Sports Management 2014;16:127-47.

[27] Zainab AT, Abedi MR, Munira S. The effect of organizational commitment and organizational citizenship behaviour on the rise. Landscape Management 2010;33:105-24.

[28] Abili K, Haiat AA, Choopani H, Keramat K. The relationship between organizational commitment and organizational citizenship behaviour experts Tehran University. Journal of Social Behaviour and Training 2011;42:67-82.

[29] Khaki G. The method of approach to the dissertation. Tehran: State Scientific Research Center 2000.

[30] Azar A, Ghollamzadeh R, Ghanavati R. path-structural modeling in management. Smart PLS Application: Negahe Danesh Publication 2011.

[31] Azar A, Momeni M. Statistics and Its application in management. Vol. 2. 10 th edn. SAMT Publication 2006. 